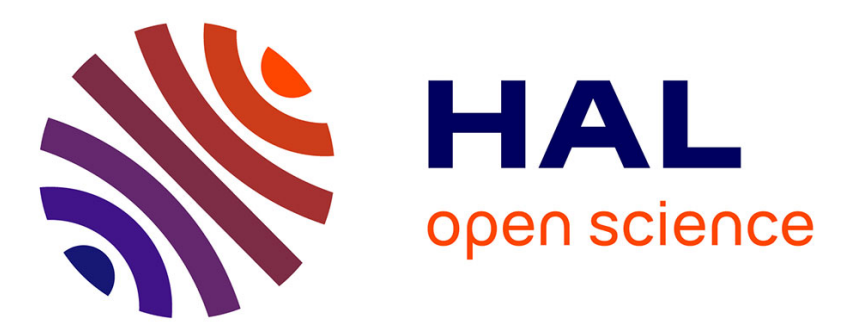

\title{
Influence of the Quenching Rate on the Spinodal Decomposition in a Duplex Stainless Steel
}

\author{
M. Hedin, J. Massoud, F. Danoix
}

\section{To cite this version:}

M. Hedin, J. Massoud, F. Danoix. Influence of the Quenching Rate on the Spinodal Decomposition in a Duplex Stainless Steel. Journal de Physique IV Proceedings, 1996, 06 (C5), pp.C5-235-C5-240. 10.1051/jp4:1996538 . jpa-00254417

\section{HAL Id: jpa-00254417 https://hal.science/jpa-00254417}

Submitted on 1 Jan 1996

HAL is a multi-disciplinary open access archive for the deposit and dissemination of scientific research documents, whether they are published or not. The documents may come from teaching and research institutions in France or abroad, or from public or private research centers.
L'archive ouverte pluridisciplinaire HAL, est destinée au dépôt et à la diffusion de documents scientifiques de niveau recherche, publiés ou non, émanant des établissements d'enseignement et de recherche français ou étrangers, des laboratoires publics ou privés. 


\title{
Influence of the Quenching Rate on the Spinodal Decomposition in a Duplex Stainless Steel
}

\author{
M. Hedin, J.P. Massoud* and F. Danoix \\ LMIE-GMP, URA 808 du CNRS, Faculté des Sciences de Rouen, Place Emile Blondel, \\ 76821 Mont-Saint-Aignan cedex, France \\ * Electricité de France, DER/EMA, 1, Route de Sens, Ecuelles, 77250 Moret-sur-Loing, France
}

\begin{abstract}
Cast duplex stainless steels are known to be susceptible to embrittlement after long term ageing at intermediate temperatures $\left(300-400^{\circ} \mathrm{C}\right)$. This embrittlement is related to the spinodal decomposition that occurs in the ferrite phase. Steels of equivalent composition after undergoing the seemingly same heat treatment exhibit different microstructural and mechanical evolutions. One of the assumptions which explains this is based on the influence of the quenching rate. For this purpose, a set of different cooling rates $\left(2^{\circ} \mathrm{C} / \mathrm{s}\right.$ to $\left.20^{\circ} \mathrm{C} / \mathrm{s}\right)$ has been applied, and the resulting microstucture analysed. The atom probe was used because of its capability to investigate the finescale $\alpha-\alpha^{\prime}$ spinodal decomposition of the ferrite. It is shown that the quenching rate influences both the initial composition amplitude in unaged specimens and the rate of development of chromium concentration fluctuations in the aged ferrite.
\end{abstract}

\section{INTRODUCTION}

Cast duplex stainless steels with ferrite-austenite microstructure are extensively used in nuclear, oil and chemical industries because, in addition to high corrosion and cracking resistance, they show highstrength and excellent weldability for large components [1].

In the mid seventies, these steels have been shown to be susceptible to embrittlement after long term ageing at intermediate temperature, i.e. 300 to $400^{\circ} \mathrm{C}$ [2]. This embrittlement is characterised by an increase in hardness and a loss of impact toughness associated with a shift of the ductile to brittle transition temperature [3]. The mechanism responsible for this embrittlement has been identified as being the so-called " $475^{\circ} \mathrm{C}$ embrittlement". Various techniques, amongst which is Atom Probe Field Ion Microscopy (APFIM), demonstrated that in the range $300-400^{\circ} \mathrm{C}$, the ferritic solid solution decomposes into $\alpha$ (Fe-rich) and $\alpha^{\prime}$ (Cr-rich) domains according to a spinodal process [4]. The resulting microstructure is a highly interconnected $\alpha-\alpha^{\prime}$ network that develops on a nanometre scale. Extensive atom probe studies demonstrated that this process is responsible for the embrittlement of stainless steels, whatever the austenite content is from 0 to at least $80 \%$. In addition, the evolution of the ferrite hardness has been linearly correlated with the spinodal amplitude. Assuming a thermally activated process, numerous studies concluded in an activation energy in the range $300-400^{\circ} \mathrm{C}$ of about $230 \mathrm{~kJ} / \mathrm{mol}$, in good agreement with that of $\mathrm{Cr}$ diffusion in $\alpha$-Fe.

If the main process responsible for embrittlement is clearly identified, many aspects affecting the rate of embrittlement remain unexplained. Indeed, large differences in the behaviour of cast duplex stainless steels and of single phase have been reported in the literature [5-7]. For example, Brown showed rates of hardening up to 50 times faster (with the same activation energy) for model $\mathrm{Fe}-26 \mathrm{Cr}-5 \mathrm{Ni}$ alloys when the homogenisation temperature was varied in the range 1250 to $1000^{\circ} \mathrm{C}$ [7]. This phenomenon was 
associated with the disappearance of the austenite from the microstructure, although no explanation could be found for it. Schwartz and LaSalle also observed different rates of spinodal decomposition for purely ferritic specimens that experienced different homogenisation temperatures $\left(1200\right.$ and $\left.850^{\circ} \mathrm{C}\right)$ [8]. From another point of view, Danoix noticed that unaged specimens taken from the bulk of an ingot exhibited a spinodal amplitude larger than that of the same specimen re-solution treated, but more rapidly quenched [5]. The same phenomenon has also been observed by Sassen [9]. In those two cases, the cooling rate was supposed to be responsible for the observed difference.

It appears that to identify the causes of those different behaviours during thermal ageing, the prior thermal history of the specimens analysed, i.e. the manufacturing, has to be taken into account. For duplex stainless steels, the consecutive manufacturing stages can be summerised as presented in figure 1 .

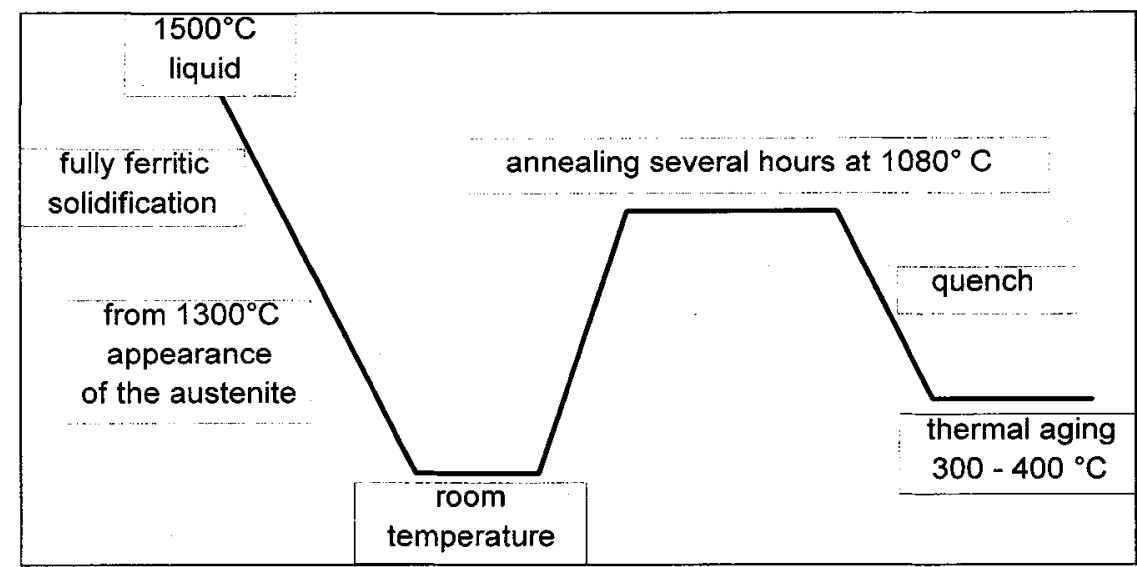

Figure 1: Manufacturing sequence of duplex stainless stell castings

The first stage is the solidification which, in the first step is purely ferritic. At this stage, the initial size and morphology of the ferrite grains is determined. Coarse equiaxed grains are observed in the core of large pieces, and fine grains, elongated in the direction of the temperature gradient during solidification at their surface. If $\gamma$-like element concentrations (mainly $\mathrm{C}$ and $\mathrm{Ni}$ ) are sufficent, part of the primary $\delta$ ferrite transforms into $\gamma$ austenite. The austenite appearance temperature is closely related to the $\alpha-$ forming over $\gamma$-forming element concentration ratio. The second step is the homogenisation treatment, the temperature of which may vary in the range 850 to $1300^{\circ} \mathrm{C}$. The annealing temperature sets the ferrite/austenite ratio of the steel, and consequently the partitioning of the alloying element in both phases. For the duplex stainless steel under investigation, the homogenisation temperature was $1080^{\circ} \mathrm{C}$, in order to form about $70 \%$ of austenite. The observations of Brown and Schwartz are most probably related to this step. The last stage is the quench of the annealed material. As previously mentioned, the quenching rate is suspected to be an important parameter influencing the initial mechanical properties and the ferrite microstructure of the material before thermal ageing.

The aim of this paper is to present initial results concerning the importance of the quenching rate.

\section{MATERIALS}

The samples studied have been supplied by Electricité de France, and their composition is given table 1. They were taken from a static cast, the thickness of which varies in the range 125 to $140 \mathrm{~mm}$. Because of that thickness, the quenching rate is inhomogeneous within the cast. It has been estimated to be about $2{ }^{\circ} \mathrm{C} / \mathrm{s}$ in the core (i.e. 60 to $70 \mathrm{~mm}$ in depth) and about $10^{\circ} \mathrm{C} / \mathrm{s}$ close to the surface. As a consequence, the position of each sample was carefully noted. Specimens under investigation referred to as " current zone » all originate at least $50 \mathrm{~mm}$ from the surface in each direction. 


\begin{tabular}{|c|c|c|c|c|c|c|c|c|c|}
\hline ELEMENTS & $\mathrm{Cr}$ & $\mathrm{Ni}$ & $\mathrm{Mo}$ & $\mathrm{C}$ & $\mathrm{N}$ & $\mathrm{Si}$ & $\mathrm{Mn}$ & $\mathrm{Fe}$ & $\begin{array}{c}\text { Ferrite } \\
\text { content }\end{array}$ \\
\hline weight\% & 21.2 & 9.7 & 2.5 & 0.032 & 0.051 & 1.1 & 0.9 & 64.6 & $30 \%$ \\
\hline atom $\%$ & 22.0 & 8.9 & 1.4 & 0.14 & 0.2 & 2.0 & 0.9 & 64.5 & $30 \%$ \\
\hline
\end{tabular}

Table 1: Chemical composition and ferrite content of the studied duplex stainless steel as measured by electron microprobe

A thin (27 mm thick) sheet of metal was taken from this last region, and re-solution treated at $1080^{\circ} \mathrm{C}$ and then water quenched. These specimens will be referred to as « re-quenched » specimens. For this thickness the cooling rate was about $20^{\circ} \mathrm{C} / \mathrm{s}$.

\section{EXPERIMENTAL}

Atom probe analyses were performed on an energy-compensated instrument [10] at $40 \mathrm{~K}$ with a pulse/standing voltage ratio of $20 \%$ in a vacuum better than $3.10^{-8} \mathrm{~Pa}$. Analysis direction was left random. In order to minimise and quantify the effects of spatial convolution between the analysis cylinder and the fine scale $\alpha-\alpha^{\prime}$ microstructure, analyses were carried out with a constant lateral resolution. The lateral resolution was kept constant at $1 \mathrm{~nm}$ using a variable iris diaphragm [11]. In order to maintain statistical fluctuations on an acceptable level, the composition of successive points on the concentration profiles are calculated over 50 atoms, corresponding to $1.2 \mathrm{~nm}$ in depth. At least 3 specimens were analysed for each heat teatment.

The extent of spinodal amplitude in the ferrite phase is quantified by the statistical distance (called variation, V) between experimental and binomial chromium concentration frequency distribution. Figure 2 shows a Cr concentration profile from the current zone aged $2500 \mathrm{~h}$ at $350^{\circ} \mathrm{C}$. On the right-hand side of the diagram, the corresponding experimental concentration frequency distribution and the difference between experimental and binomial distribution are represented.

This statistical distance is the integral area difference between the two distributions. Because these two distributions are normalised, $\mathrm{V}$ varies in the range 0 to 2 . This parameter has been shown to be an appropriate estimate of the extend of spinodal amplitude, except when smaller than about 0.05-0.1. Indeed, because of the finite size of the experimental set of data, statistical fluctuation of that order are expected, and may affect the determination of $\mathrm{V}$. Experimental values of $\mathrm{V}$ smaller than 0.1 should therefore be interpreted with care.

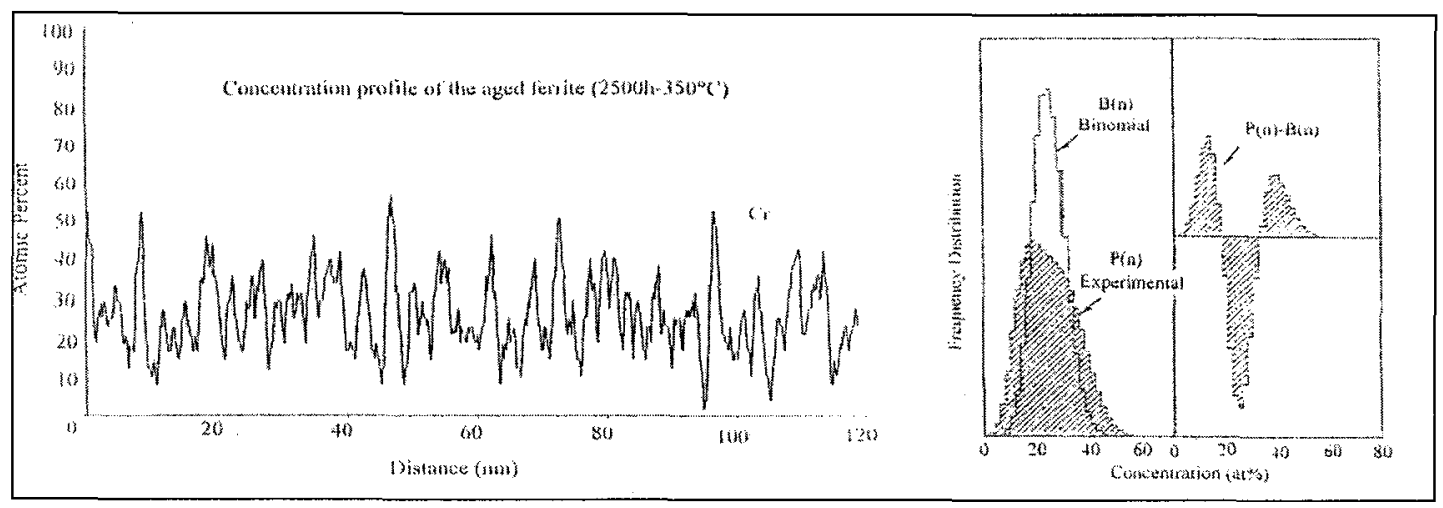

figure 2 : Derivation of the variation $V$ from an experimental concentration profile 


\section{RESULTS AND DISCUSSIONS}

\subsection{Chromium concentration amplitude as a function of specimen extraction depth}

Samples coming from different depths have been analysed in the unaged condition and after ageing $30,000 \mathrm{~h}$ at $300^{\circ} \mathrm{C}$. The cooling rate has been estimated to be about $10^{\circ} \mathrm{C} / \mathrm{s}$ for the surface sample and about $2^{\circ} \mathrm{C} / \mathrm{s}$ in the core of the elbow. The results of atom probe analyses are presented in table 2 .

\begin{tabular}{|c|c|c|c|}
\hline $\begin{array}{c}\text { current zone depth } \\
(\mathrm{mm})\end{array}$ & $\begin{array}{c}\text { quenching rate } \\
\left({ }^{\circ} \mathrm{C} / \mathrm{s}\right)\end{array}$ & $\begin{array}{c}\text { unaged } \\
(\mathrm{V})\end{array}$ & $\begin{array}{c}\text { aged } 30,000 \mathrm{~h} @ 300^{\circ} \mathrm{C} \\
(\mathrm{V})\end{array}$ \\
\hline 1 & approx. 10 & 0.05 & 0.05 \\
\hline 12 & between 2 and 10 & Not determined & 0.18 \\
\hline 60 (core) & approx. 2 & 0.19 & 0.27 \\
\hline
\end{tabular}

table 2: Variation $V$ as a function of the extraction depth and of the ageing treatment

Two important results can be derived from these data. First of all, in the unaged condition, the specimen from the core exhibits significant concentration amplitude, whereas weak (or none) is detected from the surface specimen. The second important result concerns the amplitude of fluctuations developed in both specimens after ageing $30,000 \mathrm{~h}$ at $300^{\circ} \mathrm{C}$. No significant evolution is observed for the surface specimen, whereas an increase of 0.08 occurs for the one of the core. From a mechanical point of view, these differences are associated with an important loss of impact toughness for the core specimen aged $30,000 \mathrm{~h}$ at $300^{\circ} \mathrm{C}$. Two fabrication parameters differ in both areas. The first is the microstructure resulting from solidification: in the core, coarse equiaxe grains are observed, which become elongated closer to the surface. This difference cannot directly explain either the Cr-concentration fluctuation in the " as received " conditions, or the difference in the development of fluctuations during thermal ageing. The second difference is the cooling rate experienced in each zone $\left(10 \mathrm{vs} .2^{\circ} \mathrm{C} / \mathrm{s}\right)$, which is more likely to be responsible for the observed differences.

In order to assess the influence of the quenching rate, and to eliminate a possible effect of the initial microstructure of the specimens, a second set of samples was analysed.

\subsection{Influence of the quenching rate}

In order to point out the only effect of the cooling rate, a thin plate of material has been taken from the current zone in the centre of the cast and re-solution treated at the same homogenisation temperature $\left(1080^{\circ} \mathrm{C}\right)$, and then water quenched. These specimens are referred to as « requenched» specimens. The quenching rate for this thin plate has been estimated to be $20^{\circ} \mathrm{C} / \mathrm{s}$. Specimens were aged at different temperatures and analysed by atom-probe. Results are compared with those obtained from specimens originating from the same area, but which did not receive the re-homogenisation treatment. These latter specimens will be referred to as « as received» specimens, even when they are subsequently thermally aged. The related values of $\mathrm{V}$ are presented in table 3 . Many conclusions can be drawn from these data.

\begin{tabular}{|c|c|c|}
\hline ageing treatment & $\begin{array}{c}\text { current zone « as received » } \\
\mathrm{V}_{\mathrm{q}}=2^{\circ} \mathrm{C} / \mathrm{s}\end{array}$ & $\begin{array}{c}\text { current zone « requenched » } \\
\mathrm{V}_{\mathrm{q}}=20^{\circ} \mathrm{C} / \mathrm{s}\end{array}$ \\
\hline unaged & $\mathrm{V}_{2}=0.19$ & $\mathrm{~V}_{20}=0.05$ \\
\hline $2500 \mathrm{~h}-300^{\circ} \mathrm{C}$ & $\mathrm{V}_{2}=0.06$ & $\mathrm{~V}_{20}=0.07$ \\
\hline $2500 \mathrm{~h}-325^{\circ} \mathrm{C}$ & $\mathrm{V}_{2}=0.24$ & $\mathrm{~V}_{20}=0.08$ \\
\hline $2500 \mathrm{~h}-350^{\circ} \mathrm{C}$ & $\mathrm{V}_{2}=0.58$ & $\mathrm{~V}_{20}=0.25$ \\
\hline $2500 \mathrm{~h}-400^{\circ} \mathrm{C}$ & $\mathrm{V}_{2}=1.01$ & $\mathrm{~V}_{20}=0.98$ \\
\hline
\end{tabular}

Table 3 : Evolution of the variation for « as received " and " requenched " specimen as a function of the ageing temperature 


\subsubsection{Unaged specimen}

The unaged « requenched » specimen exhibits a low V value, identical to that measured on the unaged specimen taken from the skin of the current zone. Both specimens experienced rather high quenching rates $\left(>10^{\circ} \mathrm{C} / \mathrm{s}\right)$, but have different ferrite solidification morphologies (resp. equiaxed and elongated ferrite grains). This result proves that this parameter cannot be regarded as responsible for the difference between the specimen analysed in the previous section. As a consequence, it is confirmed that the quenching rate is a key parameter for the estimation of the concentration amplitude in the unaged conditions.

\section{2 .2 "As received» specimen}

First of all, a singular point is observed after ageing at $300^{\circ} \mathrm{C}$. The concentration amplitude for this treatment is shown to be smaller than the one observed on the corresponding unaged specimen. This indicates a re-homogenisation of the decomposed $\mathrm{Fe}-\mathrm{Cr}$ solid solution. This phenomenon has already been observed, but only for annealing temperatures in the range $550-600^{\circ} \mathrm{C}$, i.e. above the $\mathrm{Fe}-\mathrm{Cr}$ miscibility gap [12]. After ageing at $300^{\circ} \mathrm{C}$, no such behaviour is expected as this temperature is well below the miscibility gap. Phase separation is expected to occur at this temperature, leading to $\mathrm{V}$ values larger than the one measured in the unaged specimen. At the moment, this result is not considered as reliable. Sample inversion is suspected, and a new set of specimens is under investigation in order to clarify this point. We will therefore not take into account this result in the course of this work. Concerning the evolution of $\mathrm{V}$ with ageing temperature, it is very similar to that observed on steel A10, a closely related duplex stainless steel we extensively analysed by Atom Probe [5].

\section{2 .3 « Requenched specimen}

$\mathrm{V}$ values remain very low after ageing at 300 and $325^{\circ} \mathrm{C}$. Only a marginal evolution is observed. It is not certain that it is meaningful, although it indicates a slight increase of the concentration amplitude with increasing ageing temperature, as expected from the spinodal decomposition theory. It is only after ageing at $350^{\circ} \mathrm{C}$ that concentration fluctuations are unambiguously detected.

\subsubsection{Comparison between " as received " and " requenched " specimen}

We represented the evolution of $\Delta \mathrm{V}=\mathrm{V}_{2}-\mathrm{V}_{20}$ after ageing at various temperatures (figure 3). Even though this value has no obvious physical meaning, it is an easy way to point out the differences in the spinodal decomposition rates between both sets of samples. The positive initial $\Delta \mathrm{V}$ value indicates the higher concentration amplitude in the "as received» conditions (cf. $\S 4-2-1$ ). $\Delta \mathrm{V}$ increase with increasing temperature up to $350^{\circ} \mathrm{C}$ shows that the rate of spinodal decomposition is larger for « as received $»$ specimens than for "requenched" ones. So, not only the initial spinodal amplitude, but also the rate of development of spinodal amplitude is strongly dependent on the quenching rate. After pronounced ageing conditions $(2500 \mathrm{~h}$ (a) $400^{\circ} \mathrm{C}$ ), both specimens exhibit similar spinodal amplitudes. From a mechanical point of view, both specimens also exhibit the same low impact toughness, already situated on the lower shelf of the ductile to brittle transition curve. It is therefore clear that the final stages of decomposition are fairly similar, and are not influenced by the quenching rate.

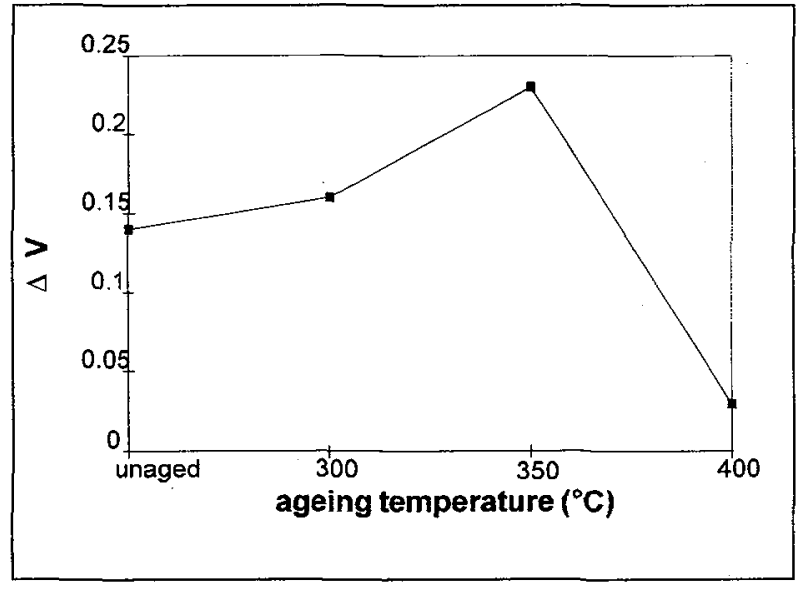

Figure 3 : Evolution of $\Delta \mathrm{V}$ after ageing $2,500 \mathrm{~h}$ at various temperatures 


\section{CONCLUSION}

This work has shown that the quenching rate of large pieces made of cast duplex stainless steel has a major influence on the spinodal decomposition which occurs in the ferrite phase during thermal ageing at temperatures in the range $300-400^{\circ} \mathrm{C}$. Indeed, it has been shown that the initial concentration amplitude observed in unaged specimen, as well as the rate of development of spinodal concentration fluctuations, increase with decreasing quenching rates. In addition, it has been shown that the morphology of the solidification primary ferrite grains has no influence on the initial concentration amplitude of the ferrite phase.

\section{References}

[1] S. Bonnet, J. Bourgoin, J. Champredonde, D. Guttmann and M. Guttmann, Mater.Sci.Technol. 6 (1990) 221-229

[2] P.J. Grobner, Trans. American Institute of Mining, Metallurgical and Petroleum Engineers 4A (1973) 251-260

[3] Proc. of Intl. Workshop on Intermediate Temperature Embrittlement Processes in Duplex Stainless Steels, Oxford, July 1989, P.H. Pumphrey, G.D.W. Smith and M. Prager Eds., Mater.Sci.Technol. Special Issue 6 (1990)

[4] M.K. Miller, J. Bentley, S.S. Brenner and J.A. Spitznagel, J.Phys. (Paris) 45-C9 (1984) 385-390

[5] F. Danoix, Thèse de doctorat de l'université de Rouen, 1991

[6] A. Trautwein and W. Gysel, "Stainless Steel Castings" ASTM-STM 756, 39 (1982)165-189

[7] J.E. Brown, P.H. Pumphrey and G.D.W. Smith, Proc Intl. Conf. on Duplex Stainless Steels, Beaune, October 1991, J. Charles and S. Bernhardsson Eds. (Les Éditions de Physique, Les Ulis, 1991) 737-746

[8] J.C. LaSalle and L.H. Schwartz, Acta Metallurgica 34 (1986) 989-1000

[9] J.M. Sassen, M.G. Hetherington, T.J. Godfrey and G.D.W. Smith, Proc. of Intl. Conf. on Properties of Stainless Steels in Elevated Temperature Service, ASME Winter Annual Meeting, Boston, 13-18 december 1987, M. Prager Ed. (New York) 65-78

[10] B. Deconihout, A. Menand, M. Bouet and J.M. Sarrau, Surface Science 266 (1992) 523-528

[11] J.M. Sarrau, F. Danoix, B. Deconihout, M. Bouet, A. Menand and D. Blavette, Appl. Surf. Sci. 76/77 (1994) 367-373

[12] F. Danoix, P. Bas, J.P. Massoud, M. Guttmann and P. Auger, Appl. Surf. Sci. 67 (1993) 348-355 